\title{
Design and implementation of internal teaching evaluation mechanism in local colleges and universities.
}

\author{
Yanhua $\mathrm{Yu}^{1, \mathrm{a}}$, Chunyan $\mathrm{Wu}^{1, \mathrm{a}}$, Jing $\mathrm{He}^{1, \mathrm{a}}$ \\ Jilin Agricultural University, Changchun,130118 \\ a64025870@qq.com
}

\begin{abstract}
Keywords: local colleges and universities, internal teaching evaluation, quality assurance
\end{abstract}
\begin{abstract}
Internal teaching evaluation mechanism is the foundation and core of the undergraduate teaching quality guarantee system. The local colleges and universities should take the quality goal as the basic principle, the connotation development as the basic goal, the prominent individuality as the main characteristic; the study result is the important basis to build up the school teaching evaluation mechanism with the three-dimensional structure which contains evaluation object, evaluation method, and evaluation function.
\end{abstract}

\section{Introduction}

The internal teaching evaluation is the foundation and core of the quality assurance system, it also an important means for the development of school connotation and the promotion of quality assurance. Along with the continuous development of higher education, the subject of quality assessment is turned from external to internal, and the research focuses on the construction of the system and mechanism of self-testing, self-repair, self-improvement. In the documents of the Ministry of Education < Opinions on the evaluation of undergraduate teaching in ordinary higher education institutions>,proposed "establish and improve the teaching evaluation system which is based on self-evaluation, to evaluation of colleges and universities, professional accreditation and evaluation, international assessment and the teaching of basic data state normal monitoring as the main content, combine the evaluation of government, schools, specialized agencies and pluralistic society, and adapt to the characteristics of modern Chinese higher education system." and "strengthen the subject consciousness of quality assurance in higher education, improve the self-evaluation system, establish and improve the quality assurance system." The purpose is to emphasize the transformation of government functions, the participation of multiple subjects, and the implementation of classification evaluation, strengthen internal security, and improve the quality of teaching. This not only provides a new perspective for the theory of quality management and evaluation of higher education, but also provides an opportunity for local colleges to improve the self-evaluation system, and to protect and enhance the quality of the school. This not only provides a new perspective for the theory of quality management and evaluation of higher education, but also provides an opportunity for local colleges to improve the self-evaluation system, and to protect and enhance the quality of the school. In order to construct the characteristics of local colleges and universities school self-evaluation system, strengthening subject consciousness of higher education quality assurance, self-improvement and continuous improvement of quality management system is established, in order to promote the teaching reform, improve the quality of personnel training, can enhance undergraduate teaching active service to the needs of economic and social development and human development needs.

\section{An overview of the research on teaching evaluation mechanism in colleges and universities}

Internal teaching evaluation is refers to the school spontaneously of internal educational environment and the quality of education in a democratic, systematic investigation process is intended to strengthen internal quality awareness, finding the problem and insufficient, to seek the sustainable development of teaching evaluation[1].In the process of higher education towards popularization, the number of domestic research on teaching evaluation and quality assurance is 
increasing, the research content is more and more extensive, and the research method is gradually expanding. One of the internal teaching evaluation is also increasing attention and research, the following characteristics and trends are mainly showed: one is about idea: pay more attention to the authenticity of the development of evaluation, more emphasis on practice, combining research and practice; the two is about content: gradually from the experience of foreign research, the significance of evaluation assessment of internal standard the value of expansion to the internal teaching evaluation mechanism, construction and actual operation of internal teaching, effective mechanism of field and category of internal teaching assessment, the three is about the evaluate method, the use of literature research, investigation based on the method, tend to take a more integrated, more personalized and tend to practice the way of action research and qualitative research methods, the forth is about the angel of evaluation , what the environmental conditions are? How teachers to teach? How to pay more attention to the students' learning? Pay more attention on students and more emphasis on return to teaching itself. As Mr. Pan Maoyuan said: "For a long time, we have neglected the study of college students as the main body of education, ignored the origin of the teaching to solve the quality problems" [2].Mr. Liu Zhentian also proposed " teaching evaluation should play a more positive role, leading to the teaching deep process, return to the real life of teaching [3].

\section{Design of internal teaching evaluation mechanism in Universities}

\section{Design principles of internal teaching evaluation mechanism in colleges and universities}

The basic point of local colleges and universities teaching evaluation is the internal of school, mainly based on the solution to the problem of the school itself. In the sense that is a school-based evaluation, so internal teaching evaluation mechanism design to school development present situation, problems and development orientation as the basis, to the school quality target to follow the basic, efforts to narrow even deliver bridge between school present situation and quality target, it should pay attention to the problem oriented. Due to the different from internal evaluation and external evaluation, diagnostic evaluation, assessment focuses on is not for rating or ranking ,studied in the process of construction and development of the existing problems and puts forward proposals for reform. Therefore, the internal teaching evaluation should be to "self-diagnosis, we can clearly know the shape, identify the problem, a clear direction, guidance, based on long-term as the basic working principle, designing a scientific index system, select appropriate assessment methods.

\section{The development of connotation as the basic purpose}

In our country higher education enters the key time of big reform, the big development, greatly improves the historical stage, the education teaching quality has been referred to the unprecedented height, more and more becomes the focal point which the society and the public pays attention. China's higher education from elite education to mass education stage only 8 years' time, the rapid development of higher education has accumulated all kinds of contradictions and problems, establish the management system and working mechanism to improve the quality of education oriented to the school, the allocation of educational resources and school work focus to strengthen teaching, improve the quality of personnel training, scientific design of internal evaluation system, the department work, teachers focus to promote the development of the school connotation, guarantee and improve the quality of personnel training. The internal teaching evaluation system construction and implementation as the connotation development, sustainable development, an important path and means of characteristic development, firmly grasp the connotation of the construction of the core elements, stimulate school development intrinsic motivation.

\section{Highlight the personality as the main feature}

Place the internal teaching evaluation system mainly based on lookup problem, take the initiative to seek development, must pay attention to guidance, outstanding personality, in the establishment of the evaluation criteria, evaluation content determined assessment should fully reflect the different needs, fully highlight the characteristics of the school, in order to evaluate the overall design has 
targeted, reflecting the tailor, "with their ruler himself" only in this way can truly desalination conclusion, focusing on the diagnosis and the result can be real to promote scientific development.

\section{Function structure of internal teaching evaluation system in Colleges and Universities}

The internal teaching evaluation system of local colleges and universities serves the aspects of the construction of the school, and its structure is the three-dimensional structure of the evaluation object, evaluation method and evaluation function (Figure1.).

One is evaluation object dimension, including students, teachers, curriculum, profession, teaching unit five levels; the second is evaluation method, and evaluation objects correspond respectively to evaluate their academic, teaching effect evaluation, curriculum evaluation, professional evaluation and teaching performance evaluation; the third is evaluation function, divided into self-monitoring, status evaluation, problem analysis, forecasting-decision and improving-promotion.

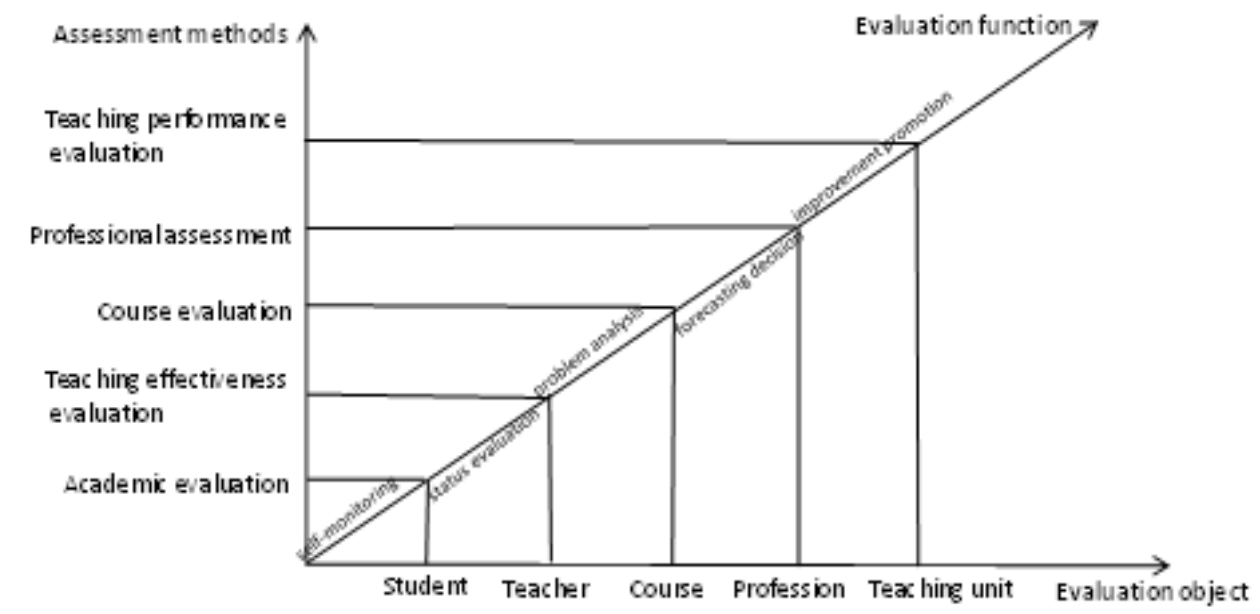

Figure 1

This three dimensional structure is a three-dimensional structure supported by three dimensions. From the beginning of the evaluation of students' academic evaluation, which means that students' learning is the most basic and core part of teaching evaluation in local colleges and universities, after the gradual expansion, each extended to the next object and the way, its assessment content is covered by the assessment of the object level and the way before. The five basic function assessment and five appraisal object and way is not one-to-one relationship, but based on the assessment of each object of evaluation methods can play at least one or several of the five basic functions, reflect the different assessment methods of complementary, also reflected internal evaluation between different evaluation objects and the inter subjective dialogue and communication.

\section{Internal teaching evaluation system in Colleges and Universities}

According to the function of internal teaching evaluation mechanism for local colleges and universities, the operation should be divided into three levels, the first level for teaching evaluation system operation, by the evaluation criteria, the evaluation process, problem analysis, information feedback. The improvement of five continuous connection components, these five areas in the cycle, the same every cycle of the program, but levels and gradually increase. The second level is the teaching evaluation support system, including two aspects of organizational structure and system security, which reflects the full participation, all-round and throughout the whole process of teaching quality assurance support mechanism. The third level is the teaching evaluation measure system, including the classroom teaching evaluation, the experimental practice inspection, and the state data collection and so on. It is the concrete measure that supports the first level and the five links. The three levels to carry out their duties, orderly convergence, mutual support, promote each other, around the quality of critical control point measurement and analysis, find out the reasons, to improve, to form a complete, interrelated, self -stabilizing system. At the same time, with the outside world keep close contact and communication, the final point quality goal realization. 


\section{The design and implementation of the internal professional evaluation mechanism of Jilin Agricultural University}

For the initiative to deal with higher education situation and regional social and economic development of talent demand changes, seek their own sustainable development, Jilin Agricultural University the school teaching evaluation mechanism construction as an important part of teaching quality guarantee system and improve the quality of education important catch hand, constructs a set of design evaluation and assessments are performed to evaluate the control, evaluation and improvement of the four parts constitute the internal professional assessment system (Figure 2), improve school teaching quality improvement mechanism. The work deeply reflects the country a new round of undergraduate teaching evaluation to the idea of the overall design of the "school subject, normal monitoring, and classification guidance", establish mechanism of self enhancement and improvement of the quality, promote the development of the school connotation and play an important role.

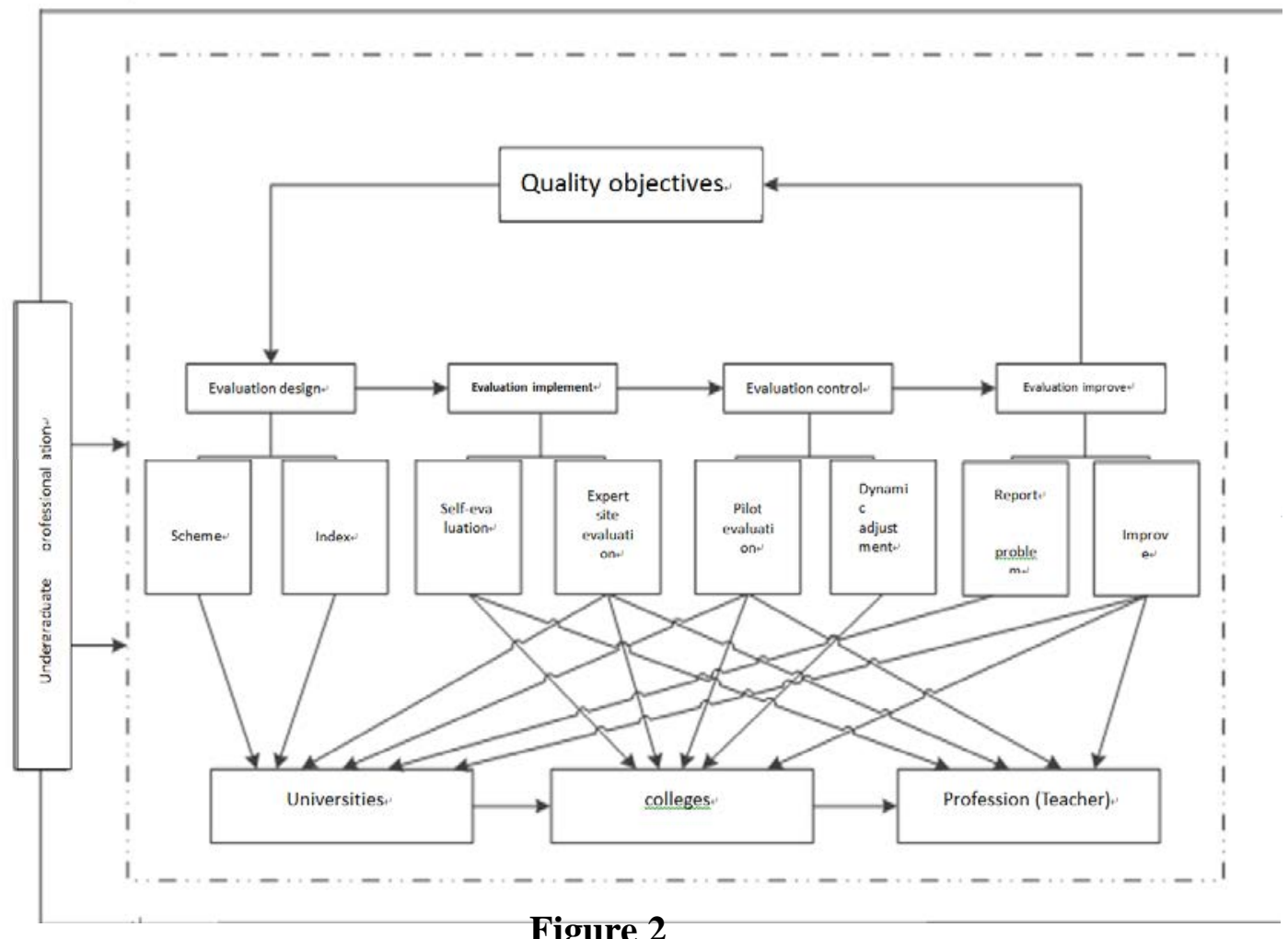

\section{Undergraduate professional evaluation design}

Undergraduate professional evaluation is based on a certain evaluation standard, the use of multiple assessment methods, on the current status of undergraduate professional development, existing problems, development trend of value judgment and evaluation guidance, is inside the school to carry out assessment activities. Adhere to the "self-diagnosis, current situation, identify the problem, a clear direction, guidance, based on long-term approach.

\section{Conclusion}

Based on the first-hand data and the school's location, we divide profession three levels, that are leader profession, profession need to be improve and the profession need to be modified .In the school of human resources, equipment acquisition, various types of project reporting and other aspects take arrangement and classification guidance. Through the professional assessment, enhance the school departments, colleges, deep understanding of all the teachers of professional construction significance and connotation, especially the college leadership, professional and responsible people, teachers and a profound understanding of the importance of self-assessment, enhance the quality awareness of all the teachers and the sense of responsibility to run professional, to enhance the 
cohesion and centripetal force of the internal of professional and college internal. In this process we build advanced concepts, ideas and initiatives, experience and achievements into school professional construction mechanism, this mechanism to evaluate as the platform and carrier, its operation result is enlightenment thinking, form a set of scientific, reasonable and feasible construction and professional development way of thinking, and thus promote the basic construction, deepening of the teaching research and reform, promote the scientific development of the professional. Lasted three years of undergraduate professional assessment by the Ministry of education, Provincial Department of education and other colleges and universities as well as peer acclaim and high degree of recognition, already became provincial colleges and universities teaching quality internal promotion mechanism model, the school strength and influence further enhanced.

\section{References}

[1] Hu Yongmei, "education theory and practice", 2004 (19): 36-40

[2] Lu Genshu. To optimize students' learning experience to improve the teaching quality of colleges and Universities -- Based on the teaching quality of colleges and universities in the perspective of students improved ways and methods to study [J]. Fudan Education Forum, 2007, (2).

[3] Liu Zhentian. The overall design and system innovation of undergraduate teaching evaluation in China: 2012 (3): 23-28 (in Chinese). 